\title{
Alfabetización algorítmica basada en la metodología de Paulo Freire
}

\author{
ROBERTO APARICI* | FERNANdo RAúl \\ Alfredo BordignON** | Jorge Martínez-PÉreZ ${ }^{* * * *}$
}

La sociedad actual atraviesa una crisis profunda Palabras clave marcada por la incertidumbre. El paradigma informacional ha ampliado los lenguajes y con ello han Incertidumbre surgido nuevos analfabetismos y conflictos sociales. En este contexto, los algoritmos son el centro del debate, ya que están presentes en casi todos los órdenes de nuestra vida. En este artículo partimos de algunos de los principios de la pedagogía freireana para aplicarlos al campo de la alfabetización alAlfabetización digital

Alfabetización

algorítmica

Pedagogía freireana

Educación y tecnología gorítmica. Una sociedad alfabetizada en los nuevos lenguajes permitirá un análisis crítico del mundo. En este sentido proponemos un conjunto de saberes digitales que posibiliten una lectura e intervención sobre la realidad.

* Profesor titular de Comunicación y Educación de la Universidad Nacional de Educación a Distancia (UNED) (España). Doctor en Educación. Publicaciones recientes: (2021, con J. Martínez Pérez, coords.), El algoritmo de la incertidumbre, Barcelona, Gedisa; (2017, en coautoría con D. García Marín), Comunicar y educar en el mundo que viene, Barcelona, Gedisa.CE: robertoaparici@yahoo.es

** Profesor asociado ordinario del Departamento de Tecnología de la Universidad Pedagógica Nacional (UNIPE) (Argentina). Doctor en Comunicación y Educación en Entornos Digitales. Publicaciones recientes: (2021, en coautoría con L. Dughera), "Accesos, usos y percepciones sobre contenidos audiovisuales en YouTube. Una mirada a estudiantes de escuelas secundarias técnicas", Revista Hipertextos, vol. 9, núm. 15, pp. 125-142. DOI: https://doi.org/10.24215/23143924e031; (2020, en coautoría con D. Daza Prado, C. Di Próspero, L. Dughera y F. Peirone), "Exploración de las estrategias de aprendizaje tecnosocial entre los y las jóvenes ingresantes a la educación superior. El caso UNIPE/UNPAZ/UNSAM", Propuesta Educativa, vol. 29, núm. 53, pp. 9-24. CE: fernando.bordignon@unipe.edu.ar

*** Docente e investigador en la Universidad Internacional de Valencia (VIU) (España). Doctor en Educación. Publicaciones recientes: (2021, con R. Aparici, coords.), El algoritmo de la incertidumbre, Madrid, Gedisa; (2017, en coautoría con J. Quintana), "El empoderamiento del alumnado en los sMOOC”, Revista Complutense de Educación, vol. 29, núm. 1, pp. 43-60. DOI: https://doi.org/10.5209/RCED.51932.CE: jorgemp88@gmail.com 


\section{INTRODUCCIÓN}

En el marco de la sociedad informacional, resulta más necesario que nunca retomar los principios de la pedagogía freireana para aplicarlos al campo de la alfabetización algorítmica.

En este artículo partimos de algunos de los principios de Paulo Freire y los aplicamos al campo digital. La alfabetización algorítmica basada en la metodología de Paulo Freire es el anticipo de un futuro libro. Un proyecto que el grupo de investigación que escribe estas líneas habrá de publicar a lo largo del próximo año, fruto precisamente del trabajo llevado a cabo para la redacción de este artículo.

En la tercera década del siglo XXI, la alfabetización algorítmica abre una puerta a la posibilidad de mejorar la calidad de vida de la ciudadanía en todos los ámbitos. Leer el mundo desde los algoritmos es una oportunidad para entender mejor los retos que se nos presentan como ciudadanos de la aldea global.

En un primer apartado, en primera persona, el profesor Roberto Aparici establece el inicio de un recorrido sobre el camino de la alfabetización. A continuación, apelando a un diálogo entre Seymour Papert y Paulo Freire, se presenta una problematización relativa a los cambios tecnológicos y la emergencia de una sociedad algorítmica. Luego, de manera propositiva, se aborda el tema de los saberes digitales, los cuales emergen como una serie de rumbos en la alfabetización en tiempos del paradigma informacional.

\section{Primer enCuentro CON la Alfabetización}

Mi primer encuentro con Freire tuvo lugar en Argentina. Yo fui uno de los miles de alfabetizadores voluntarios que participó en la campaña organizada por la dirección de adultos de ese país.

Era un maestro recién egresado que junto con otros jóvenes voluntarios habíamos recibido un curso de entrenamiento para desarrollar el método de Freire con población adulta en un medio urbano, como es Buenos Aires. Las campañas de alfabetización se realizaban en centros de trabajo, en fábricas y en diferentes empresas que cedían tiempo y espacio para la formación de sus trabajadores de manera retribuida.

A mí me correspondió formar a operarios de la carne en el frigorífico Lisandro de la Torre en el barrio de Mataderos, un barrio popular donde el índice de analfabetismo era alto. Recuerdo que ese primer día, 50 años atrás, los alumnos me esperaban con emoción. Tanto para ellos como para mí, significaría un antes y un después en nuestra vida personal y profesional.

Empezar como voluntario en la tarea de alfabetización con el método de Freire determinaría mi futuro: estar cerca de los excluidos, acompañarlos en su proceso de liberación. Junto con esos trabajadores que no sabían leer ni escribir comenzamos a leer el mundo, lejos del mundo burgués en el que yo había vivido hasta entonces. Empezamos a leer los códigos de la marginación, de los desposeídos, de los nadie en palabras de Galeano. Ese 
grupo de trabajadores me enseñaría a leer la realidad en la que vivía y en la que viven los desposeídos, los parias.

El punto de partida era encontrar la palabra generadora para construir el universo vocabular en la historia de estos seres humanos marcados por la explotación y el sufrimiento. En ese contexto, la palabra generadora, la palabra con la que comenzamos a aprender a leer y escribir el mundo fue "carne".

Esta palabra tiene una historia per se en la historia argentina, una historia de ganaderos, empresarios, peones... una historia marcada por la economía, la sociología, la literatura, los medios de comunicación... Existía un universo vocabular muy amplio en el que se incluían cuentos populares, historias de vida, poesías...

Teníamos una hora todos los días. Eran mis primeros alumnos. Yo no sabía qué iba a ocurrir o cómo iba a ocurrir ese descubrimiento de la palabra; sólo contaba con unas prácticas previas como maestro hechas con niños y jóvenes en la escuela de Magisterio.

Recuerdo que un viernes se produjo el descubrimiento de la palabra. Este grupo de estudiantes analfabetos empezó a leer. Estos hombres fuertes, curtidos por el dolor y el sacrificio, se enternecieron con el descubrimiento de la palabra y me decían: “imaestro!, ¡maestro! ¡Sé leer!, ¡sé leer!”. Entendí en ese momento que comenzaba un proceso de autonomía y de liberación.

Las siguientes semanas profundizamos en algunos aspectos de lectura y de escritura y nos despedimos con un profundo abrazo. Nunca más supe de ellos. Hoy los recuerdo, 50 años después, en esta tarea de pensar a Freire, la alfabetización y los algoritmos.

A partir de esta tercera década del siglo XXI, el mundo requiere que, como hace 50 años, enseñemos a leer y escribir los nuevos códigos. Ya no es suficiente aprender a leer y escribir códigos alfanuméricos; es imprescindible aprender a leer, escribir, analizar, reflexionar y crear con los signos de nuestra época.

Y también es necesario pensar cuáles son las nuevas palabras generadoras de este tiempo. Aquéllas que problematizan nuestro presente, que nos convocan y, a la vez, nos interpelan para seguir luchando por una sociedad de iguales. Así, palabras como algoritmo, sesgo, plataforma y vigilancia, entre otras, son candidatas a ser consideradas en las nuevas demandas de alfabetización, ya que problematizan nuestra cotidianeidad.

El proceso de alfabetización algorítmica no es para formar informáticos ni programadores. Es un proceso para enseñar a leer la vida, a leer los acontecimientos, a leer el mundo que viene, que está ya aquí... y también para estar preparados para escribir con los lenguajes de este tiempo porque si no sabemos escribir algoritmos otros los harán por nosotros, y marcarán caminos que no son nuestros y destinos donde posiblemente las asimetrías y las brechas sociales se incrementarán.

Como bien dice Manuel Castells (1998), sin una adecuada alfabetización que dialogue con esta configuración particular del mundo vamos a reproducir generaciones de interactuados por los algoritmos en lugar de ciudadanos interactuantes, es decir, aquéllos que son capaces de superar 
las opciones preempaquetadas y escribir las suyas con los nuevos lenguajes de los algoritmos.

Así, en este contexto, si no tenemos las mínimas competencias en alfabetización algorítmica, seremos seres aislados, manipulables, marginados, como lo fueron los analfabetos de épocas pasadas.

\section{EL NUEVO ANALFA BETISMO ES EL ANALFABETISMO DIGITAL}

En ese momento, la tarea principal de mi vida era enseñar a leer y escribir a personas que habían quedado fuera del sistema y no podían entender muchos de los acontecimientos que ocurrían en el mundo. No podían expresarse sobre la realidad de manera escrita y eran fácilmente manipulados. No podían leer el paisaje y tampoco tenían voz para expresarse. Ahora que escribo este artículo, y al revivir ese momento histórico, tomo conciencia en un momento diferente, 50 años después.

Estamos ante un nuevo desafío: algo codificado como las palabras, las letras o, en su momento, las imágenes. De la misma forma que el método de alfabetización de Freire partía de la palabra generadora, a finales del siglo Xx la imagen constituyó el epicentro de la alfabetización en el lenguaje de los medios de comunicación. Y ahora, en esta tercera aproximación al método de alfabetización de Freire, ese universo vocabular parte del algoritmo, uno de los códigos del mundo digital. Las palabras fuerza que iniciaron el proceso de alfabetización a lo Freire ahora nacen, en el universo digital, en la red de redes, en palabras abstractas que requieren del ideario individual y colectivo para construir su significación a partir de la liquidez de los tiempos post pandémicos. Los elementos que se hacen presentes en la alfabetización algorítmica conllevan una necesaria conceptualización de nuevos términos, de un nuevo léxico: digitalización, motores de búsqueda, algoritmo, capitalismo de la atención, automatización, capitalismo de plataformas e interfaz, entre otros.

Desde mi perspectiva, más allá de las innumerables citas y las diversas interpretaciones de su pensamiento, el método de alfabetización de Freire se puede dividir en cuatro grandes ideas:

- Alfabetizar es concienciar

- Alfabetizar es dialogicidad

- Alfabetizar es tener voz, decir tu palabra

- Alfabetizar es leer el mundo, comprender sus paisajes

El camino hacia la alfabetización propuesto por Freire se inicia con la búsqueda de palabras que desencadenan en temas generadores, en centros de interés en la relación entre educador y educando. A continuación, será necesario codificar estas palabras en imágenes visuales que faciliten el empoderamiento del educando y le den voz en su propio proceso. A su vez, el contexto cultural que rodea a la persona es el punto de partida. Volver a Freire es recuperar la importancia del diálogo, porque nos hace más 
humanos. Es necesario humanizar el aprendizaje. El proceso no termina; se construye día a día y, por ello, como siguiente fase se fomentará la codificación creativa para una participación real desde el pensamiento crítico, con el fin último de ser actores de la transformación social.

Entre la cantidad de libros, artículos, publicaciones y encuentros dialógicos que componen la obra de Freire, rescatamos un diálogo que, si bien es poco conocido, nos proporciona reflexiones acerca de la educación, la tecnología y el mundo contemporáneo.

\section{TECNOLOGíA Y EDUCACIÓN}

A finales del siglo XX tuvo lugar un encuentro entre Freire y Papert, autor de la teoría del aprendizaje construccionista y promotor de las actividades educativas con computadoras al servicio de la construcción de conocimientos. El diálogo tuvo lugar en São Paulo, Brasil. ${ }^{1}$

Una joven estudiante se acercó al profesor después de la clase y le preguntó: “qué he aprendido hoy?”, y el profesor le respondió: "esa es una pregunta graciosa. ¿Por qué me preguntas eso?”. La niña respondió: “cuando llegue a casa, papá me preguntará: ¿qué has aprendido hoy? Y nunca sé qué responder”.

Así comienza esta entrevista que promueve una profunda reflexión acerca de la integración de las tecnologías digitales en la escuela desde una posición que invite a pensar en la educación desde otra perspectiva. A su vez, esta reflexión asentará principios que se utilizarán para pensar este presente de la educación en medio de un contexto tecno-social situado en la emergencia del paradigma informacional (Castells, 2001), donde los algoritmos son los nuevos engranajes que están reemplazando, poco a poco, a los del paradigma industrial, cuando Freire desarrolló su obra.

Durante la entrevista se pone en tela de juicio la concepción y demanda social acerca del aprendizaje en la escuela como un depósito de contenidos que otorgue al estudiante un conjunto de saberes estáticos, aislados y deslocalizados cuya adquisición pueda ser evaluada mediante sistemas de medición estandarizados. Freire propone una "educación revoltosa”, con el fin de inquietar a los actores educativos, muy diferente de la escuela conservadora que intenta acomodar sus vidas a un mundo particular. ¿Cómo las nuevas tecnologías, que en su origen parten de la comunicación horizontal, han promovido esto?

Freire defiende una pedagogía de la pregunta y no de la respuesta; la curiosidad de los alumnos en contraposición a un modelo bancario (Freire, 1970). En el encuentro con Papert, Freire afirma:

...estoy a favor de una pedagogía de la curiosidad. Por eso defendí, con el filósofo chileno Fagundes, una pedagogía de la pregunta y no de la respuesta. Es precisamente la pedagogía que se basa en esta curiosidad, sin la cual no hay pedagogía y que aumenta esta curiosidad.

${ }^{1}$ El video de la entrevista puede verse en: https://www.youtube.com/watch?v=eHU8bol xs9s (consulta: 15 de septiembre de 2021). 
En los orígenes de los seres humanos, la educación primigenia era promovida por la necesidad de aprender desde la experiencia, la curiosidad y la supervivencia, muy similar a la forma de aprender de un bebé que, desde sus primeros días, es capaz de ver la realidad a través de actividades de exploración, en un proceso que es impulsado por el propio individuo. Se trata de un proceso autodirigido: hablamos de aprendizaje real, es decir, de aquél que de forma natural se basa en la curiosidad y que desgraciadamente, cuando la escuela entra en acción, es relegado a un segundo plano a favor de una concepción denominada "enseñanza", bajo la cual, en palabras de Papert: "los niños son destruidos y asfixiados".

La escuela no es el lugar adecuado para una alfabetización en pleno siglo XXI que tenga en cuenta las enseñanzas de Papert y Freire; se trata de una educación de otra naturaleza, necesaria para todos los miembros de la sociedad, independientemente del momento vital o la situación social en la que estén.

La escuela se asocia a la enseñanza en detrimento del aprendizaje, a pesar de que son conceptos vinculantes. La prioridad ejercida sobre el primero hace que el foco se ponga en el profesor y no en los estudiantes; en los contenidos y no en la experiencia; en las materias como compartimentos estancos (Aparici y García-Marín, 2018) y no en la interdisciplinariedad; en la reproducción y no en la creatividad; en la asimilación y no en el pensamiento crítico. Todos estos conceptos remiten a la obra de Freire y, además, invitan a pensar en la educación en la era del algoritmo.

Uno de los puntos centrales de la entrevista es la discusión que se produce sobre educación y tecnología, ya que ahí se pone de manifiesto el rol que tiene esta última en el aprendizaje; un conocimiento ajeno a la escuela, pero que permite automatizar habilidades y ejecutar acciones sencillas de interacción.

Papert afirma:

...no hay nada más ridículo que la idea de que la tecnología puede mejorar la escuela. Sustituirá la escuela que conocemos. Esperamos que siempre haya lugares para que los niños se reúnan con la gente para aprender. Pero la naturaleza fundamental de la escuela en ese proceso está terminada y, en 10, 20 años, cosecharemos los resultados... en ese ámbito, las cosas suceden generalmente más rápido, así pues, el objetivo de los educadores debería ser buscar nuevas formas de tratar con los niños y de relacionarse dentro del triángulo adultoniño-conocimiento. Necesitaremos formas muy diferentes y, por supuesto, esto no ocurrirá de forma fácil y automática.

Más adelante, Freire replica:

Una de las tareas centrales de la escuela es el conocimiento de los saberes ya existentes y la producción de saberes aún no existentes. Éstas son las dos tareas principales de la escuela: proporcionar el conocimiento del conocimiento ya existente y producir el conocimiento aún no existente...

Una cosa es ser contemporáneo de un determinado avance tecnológico y otra cosa es llegar antes de un avance tecnológico... miro los ordenadores 
y me asombro, ¿sabes? Es maravilloso, ipero no soy coexistente! No soy contemporáneo. Y ese peso... flota en el aire... La atmósfera histórica está llena de computación. Está llena de teléfonos... Es decir, hay una historia de hechos que impregna los hechos. El problema es el siguiente: ¿cómo trabajar la necesaria promoción del conocimiento desde el conocimiento común, desde el sentido común, hasta el conocimiento más metódicamente riguroso de la ciencia, sin la correcta organización de una entidad para ello?

... soy un contemporáneo de la escuela... ¿Ves el problema? No tengo una respuesta, pero me reto a pensar en ello... Porque no es sólo el acto de manejar el ordenador lo que me permite entender su razón de ser.

Papert, casi al finalizar la entrevista, agrega:

Luego, alrededor de los años ochenta, el ordenador llegó a las manos de las administraciones escolares, de los ministerios, de todo lo que llamamos agentes educativos. Lo que ocurrió fue que el ordenador dejó de estar en manos del profesor visionario; ahora todos los ordenadores están en el aula, existe el aula de informática, un plan de estudios y un profesor de informática específico... En resumen, se integró por completo en la idea y la forma de hacer las cosas en la escuela.

Papert y Freire ponen al descubierto que la tecnología ofrece distintos modelos de aprendizaje; desde una postura democrática, y atendiendo al valor interrelacional, permiten el acercamiento a una nueva manera de leer el mundo en la que las instituciones educativas pueden beber del aprendizaje informal; en la que existen muchos caminos para alcanzar el objetivo de una escuela humanista (Stramiello, 2005), democrática y que dialogue con su contexto (Dewey, 1995).

Una educación en la que la tecnología se convierta en una poderosa herramienta, independiente del mercado, que sea el medio a través del cual se recuperen los valores freireanos amparados en el descubrimiento, la curiosidad, la creatividad y la libertad.

La crisis sanitaria derivada de la COVID-19, a escala mundial, hace visible el modelo tecnocrático facilitado por la tecnología que inunda las aulas; un modelo educativo mediado por la tecnología para mantener la reproducción social. A diferencia de la pedagogía de Freire, se sigue sustentando el modelo industrial, se mantienen las prácticas de la educación bancaria. Es importante hacer hincapié en cómo los algoritmos están funcionando como los "engranajes" de este tiempo para sostener y perpetuar, en muchos casos, prácticas educativas que dialogan de manera estrecha con la escuela de la modernidad.

En los últimos 20 años se han seguido repitiendo los mismos modelos en las escuelas, mientras que, en el resto de los ámbitos de nuestro constructo social, se han dado cambios: vivimos otras realidades influidas por los algoritmos, el procesamiento de los grandes datos y las plataformas de Internet.

El gran desafío que se presenta es dar el salto a la alfabetización, educar a la ciudadanía en los nuevos lenguajes, pero siempre siguiendo ese enfoque liberador que problematice en cada ciudadano los problemas de su tiempo. 
Así como en la lectoescritura se alfabetiza en códigos visibles, de naturaleza lineal, con los algoritmos se trata de alfabetizar en códigos de otra naturaleza, en términos de Freire, con otra significación: abstracta, intangible, líquida. Alfabetizar en algoritmos es como enseñar a leer y escribir: una competencia básica para cualquier individuo, para poder comprender y entender el mundo en el que se desenvuelve.

\section{LECTURA DEL MUNDO: ALgORITMOS Y FREIRE}

Para leer el mundo en esta tercera década del siglo XXI se propone alfabetizar algorítmicamente recuperando la esencia freireana; para ello se hace necesario volver a sus principios y aplicarlos en el proceso de alfabetización para alcanzar los conocimientos mínimos que permitan leer, analizar, reflexionar, crear y transformar en la sociedad digital. En suma, recuperar la voz en términos de ciudadanía digital.

En esencia, el encuentro entre Papert y Freire muestra cómo la escuela enseña, pero no alfabetiza. En este proceso de enseñanza, las prácticas educativas y la cultura institucional matan la curiosidad innata de los seres humanos. Para estos autores la tecnología no sustituirá la escuela, pero sí la cambiará.

En el proceso de alfabetización algorítmica se deben considerar, al menos, tres dimensiones: los espacios en los que se desarrollará, quién lo pondrá en marcha y cómo se ejecutará. Se trata de una alfabetización dirigida al conjunto de la población mundial; un aprendizaje esencial para comprender los elementos mínimos de los códigos de nuestra época. Es un tipo de alfabetización básica que permite entender los nuevos lenguajes algorítmicos, cómo se construye la realidad y cómo los algoritmos influyen en el día a día. Es imprescindible tener conocimientos básicos para poder leer y entender el mundo.

Para educadores, comunicadores y profesores de diferentes disciplinas se requieren destrezas que faciliten el proceso de alfabetización. Para informáticos y programadores, un nivel profundo de conocimiento que está más allá de la alfabetización y que entra en el campo de la especialización algorítmica, lo que les permite construir y deconstruir mensajes de esta naturaleza. El aspecto ético y normativo deberá ser reflexionado y desarrollado desde la alfabetización algorítmica sin perder la perspectiva humanista. Como ya dijimos, alfabetizar en algoritmos implica adquirir una competencia básica que nos permita comprender y entender el mundo.

La propuesta que se lanza desde aquí es alfabetizar algorítmicamente recuperando la esencia freireana. Tal como se recoge líneas más arriba, la vida está llena de pantallas. La proliferación de dispositivos digitales interconectados a través de redes sociales y plataformas está forjando entre sus usuarios un intercambio de datos cuyo precio es ser vigilados y controlados sin necesidad de utilizar elementos visibles para ello:

...hay una cuestión que toma más vigencia que nunca y es que mientras

McLuhan afirmaba que los medios eran extensiones de los seres humanos, se 
subraya que más que extensiones ya forman parte de nosotros, somos adictos a estos objetos. Son cómo órganos integrados en nuestro cuerpo (Aparici y Martínez-Pérez, 2021: 68).

Además, en línea con la propuesta de García Canclini (2020), la opacidad de los algoritmos y la transparencia de nuestros datos forman un vínculo asimétrico y desigual que pone en duda nuestra capacidad de desempeñarnos como ciudadanos.

Pero más allá de las reflexiones anteriores, se puede decir que los dispositivos son una parte de nuestro ADN. En pleno siglo XXI se vive bajo la influencia de la inteligencia artificial y el clickbait, que no hace sino aprovechar titulares sensacionalistas para promover en los usuarios el interés por hacer clic en sus contenidos y generar ingresos a partir de un titular que, en algunas ocasiones, poco o nada tiene que ver con la noticia que lo acompaña. Se promueve que

...la sustitución de la intersubjetividad dialógica por la virtualidad tecnocrática pueda generar un abismo entre las voluntades de los ciudadanos y las órdenes e informaciones de una realidad virtual y virtualizada; es decir, una virtualidad sin sujetos y, por tanto, aprisionada a los clickbaits con informaciones intencionalmente plantadas (Pizzi, 2018: 34).

Por otro lado, el avance de las plataformas, objetivado en la refinación de los procesos de captura de datos, análisis automático y predicción, presenta una realidad de alta preocupación para la ciudadanía, tal como indica Zuboff:

El capitalismo de la vigilancia emplea muchas tecnologías, pero no podemos equipararlo a ninguna. Puede que, para sus actividades, utilice plataformas, pero esas actividades no son lo mismo que las plataformas de las que se vale para ellas. Emplea inteligencia de máquinas, pero no es reducible a esas máquinas. Produce algoritmos y depende de ellos, pero capitalismo de la vigilancia y algoritmos no son lo mismo. Los singulares imperativos económicos del capitalismo de la vigilancia son los titiriteros que se ocultan tras el telón dirigiendo las máquinas y haciendo que actúen (Zuboff, 2015: 184).

Existen múltiples amenazas invisibles que son capaces de modificar la toma de decisiones y alterar conciencias, y que pueden convertir a la ciudadanía en títeres del mercado; no se comprende que se pierde el derecho a la libertad por una falta de alfabetización algorítmica y digital que, de haberla, se mostraría implacable ante el avance de los monstruos en forma de códigos binarios que condicionan nuestra cotidianeidad.

La incursión de grandes compañías como Google, Facebook, Amazon o Apple en la educación exige un proceso de reflexión crítica por parte de la comunidad educativa y, a su vez: 
La nueva normalidad educativa está, si cabe, más vinculada a la tecnología que nunca, más dependiente de las big tech que nunca, y más desamparada y huérfana de ideas alternativas que nunca. Una vez más nos encontramos con un sistema educativo a la deriva y receptor pasivo de cualquier nueva propuesta procedente del sector privado que pueda venderse como nueva innovación a una sociedad que no se muestra capaz de despertar... (Martínez-Pérez y Aparici, 2021: 68).

La plataformización de la educación alimenta el capitalismo de la vigilancia y eso no es bueno para el sistema educativo público ni para los ciudadanos, porque los fines están más cercanos a los del capitalismo informacional que a brindar una mejor educación. En palabras de Zuboff:

Todo depende de alimentar los algoritmos que puedan aguijonear a cada uno de ellos con eficacia y precisión, y no soltarlos. Todo ese desembolso de ingenio y dinero va dirigido a ese exclusivo objetivo de mantener a los usuarios - y a los jóvenes, en especial- pegados al espejo social como insectos en un parabrisas. Este fenómeno es más peligroso, si cabe, por el hecho mismo de no tener precedentes (Zuboff, 2020: 486).

La alfabetización algorítmica tomará el sentido que sus promotores le quieran dar. Habrá tantos modelos como entidades, organizaciones, empresas o movimientos sociales se impliquen en este reto. Frente a lo que puedan ofrecer gigantes tecnológicos como Google, Amazon, Microsoft o Facebook, entre otros, este movimiento tendrá que comenzar por hablar de gobernabilidad digital y formación de la ciudadanía en este campo para evitar la creación de un nuevo orden económico como lo describen Van Dijck y Poell:

Los mecanismos de dataficación y comoditización, adaptados del ecosistema de las plataformas sociales, pueden presagiar un cambio profundo en la organización de la educación... Es imposible predecir hasta dónde penetrará la dinámica de la "plataformización" en las estructuras tradicionales de la educación superior, pero podemos señalar tres posibles implicaciones a partir del análisis anterior. En primer lugar, las plataformas educativas tienden a supeditar sus principios pedagógicos a los mecanismos de las redes sociales; en segundo lugar, los softwares educativos y los sistemas de seguimiento de datos en las escuelas y universidades no han sido puestos a prueba lo suficiente para demostrar su eficacia, pero de todas formas se los presenta como soluciones necesarias frente a instituciones educativas obsoletas; en tercer lugar, la incorporación de la educación online en un mundo global de plataformas comerciales de alta tecnología puede transformar la idea de educación como bien público (Van Dijck y Poell, 2018: 587. Traducción libre).

Difícilmente la escuela podrá desarrollar un movimiento de liberación tal como afirmaban Freire y Papert, dadas las diferentes agendas geopolíticas en las cuales se deberán trabajar saberes digitales que sirvan de base para la alfabetización algorítmica. 


\section{SABERES DIGITALES Y ALgORITMOS}

En su obra Pedagogía de la esperanza, en un pasaje Freire se refiere específicamente a los saberes técnicos de los trabajadores. En particular dice:

Esa es la manera necesariamente estrecha de capacitar que a la clase dominante le interesa, la que reproduce a la clase trabajadora como tal. En la perspectiva progresista, la formación técnica también es una prioridad, naturalmente, pero a su lado hay otra prioridad que no puede ser puesta al margen. El obrero que está aprendiendo, por ejemplo, el oficio de tornero, de mecánico, de albañil, de carpintero, tiene el derecho y la necesidad de aprenderlo lo mejor posible, pero tiene igualmente el derecho de saber la razón de ser del propio procedimiento técnico. Tiene el derecho de conocer los orígenes de la tecnología, así como el de tomarla como objeto de su curiosidad y reflexionar sobre el indiscutible adelanto que ella implica, pero también sobre los riesgos a que nos expone... Ésta es, sin duda, una cuestión no sólo profundamente actual, sino también vital de nuestro tiempo. Y la clase trabajadora no debe formar parte de ella simplemente como el obrero de Tiempos modernos que se ve ocupado en el acto de apretar tornillos, en la producción en serie...

Lo que me parece fundamental para nosotros hoy... es la asunción de una posición crítica, vigilante, indagadora, frente a la tecnología. No endemoniarla ni endiosarla.

La frase casi hecha - ejercer el control sobre la tecnología y ponerla al servicio de los seres humanos- tal vez jamás tuvo tanta urgencia de concretarse como hoy, en defensa de la libertad misma, sin la cual el sueño de la democracia se diluye (Freire, 1993: 126).

De las palabras de Freire se extraen pistas que inspiran una reflexión sobre la vida social y subjetiva de cada ser humano en general y, en particular, sobre cómo ésta se ve atravesada actualmente por las tecnologías digitales. Hoy, debemos comprender cómo las personas pueden desarrollarse, de manera superadora, en esta configuración sociotécnica tan particular, donde el paradigma informacional impulsa nuestro mundo laboral desde tres fuerzas principales (Zukerfeld, 2020):

- La informacionalización, entendida como la digitalización de la vida, como la generación de archivos esencialmente compuestos por números que en definitiva son procesados por algoritmos y que permite avances significativos en nuestra dimensión cognitiva.

- La plataformización, entendida como la recreación del mercado tradicional en el espacio digital, en la que la función de los algoritmos es gestionar la relación entre humanos a partir de artefactos que están presentes en nuestra cotidianeidad, como las aplicaciones Uber, Coursera o Airbnb.

- La automatización, entendida como la sustitución de procesos de manufactura manual por procesos llevados a cabo por computadoras. 
De la misma forma que, en su momento, la lectura de imágenes es el punto de partida para la alfabetización del lenguaje de los medios de comunicación, los saberes digitales (Bordignon, 2019) pueden ser entendidos como el paso previo, la prealimentación necesaria para iniciar el proceso de alfabetización algorítmica de la ciudadanía. Más allá de la dimensión técnica, la alfabetización en saberes digitales permite hacernos preguntas sobre la enseñanza del uso de artefactos que aún no se han inventado, así como en las relaciones que se establecen.

Durante la época denominada "TIC" el foco de la alfabetización estuvo centrado en una exploración de artefactos tecnológicos, centralmente herramientas de software. Se pensaba que éstos, por sí mismos, podrían colaborar con prácticas docentes que derivarían en mejores aprendizajes. Una solución que, en general, no arribó a la docencia; por un lado, porque faltaron rumbos claros de exploración, y por otro, debido a que el mercado alimentó de manera excesiva el mapa del territorio explorado.

En la actualidad es necesario inaugurar una nueva época donde se ensaye una mirada educativa superadora de la alfabetización, teniendo en cuenta que se vive un tiempo atravesado por algoritmos y automatizaciones que pueden ayudarnos a un mejor desarrollo social pero que, como contrapartida, se constituyen como elementos del capitalismo informacional que promueve mayores asimetrías sociales. Así, desde la mirada alfabetizadora, se debe trabajar en la promoción de una época "post TIC", donde el eje central sea ayudar a que la ciudadanía pueda "habitar" y resolver problemas de su tiempo, problemas que la interpelen, que la inspiren y, a la vez, que la motiven.

Si en épocas del paradigma industrial las actividades basadas en ejercitación eran las que habitaban en mayor medida las aulas de la educación obligatoria, hoy, en tiempos del paradigma informacional, es imperativo superar tales limitaciones educativas, y para ello es necesario promover prácticas de alfabetización donde, más allá de los ejercicios, se habiten los problemas, entendidos como aquellas situaciones donde no todo está explicitado, donde hay incertidumbre y en las que no existe un camino preciso hacia una - o varias-soluciones.

Así, la capacidad de resolución de problemas es el inicio de la alfabetización algorítmica: de nada sirve desarrollar saberes que terminan siendo funcionales a una tecnocracia, si no hay un abordaje basado en una situación problema.

Con la finalidad de iniciar una alfabetización algorítmica post TIC, se propone el concepto de "saberes digitales" como un marco de pensamiento educativo, cercano a las ideas freireanas, que ayude a la construcción de un rumbo superador que dialogue tanto con el paradigma informacional como con las necesidades puntuales de los distintos contextos en los que se desarrolla la ciudadanía.

En este marco, los saberes digitales se entienden como un conjunto de habilidades instrumentales, comprensivas y actitudinales que derivan del paradigma informacional y que, en particular, permiten consumir, reelaborar, crear y compartir contenidos interactivos y reflexionar sobre algunos tópicos en relación con este tipo de tecnologías. 
En esta nueva época se propone no hablar, en principio, de artefactos tecnológicos, en particular de aplicaciones que la ciudadanía debería conocer y utilizar en el camino de la alfabetización algorítmica; en cambio, es de vital interés centrar la mirada en tres ejes principales que pueden impulsar esta nueva alfabetización:

- Un primer eje de los saberes digitales se denomina resolución de problemas con tecnologías. Se propone el desarrollo de capacidades orientadas a la comprensión, diseño y resolución de situaciones problema, de manera que los problemas sean entendidos como situaciones en las que existe un grado de incertidumbre y donde no necesariamente hay soluciones conocidas.

En este eje están presentes temas como el pensamiento computacional y la alfabetización en el desarrollo de algoritmos y programas, aspectos que deberían conversar con aquellos conocimientos digitales informales que los actores educativos portan. De esta manera, se visibiliza la diversidad de conocimientos que la ciudadanía ya ha construido en su cotidianeidad con recursos propios de la educación informal.

- Un segundo eje es el denominado expresión con tecnologías, centrado en que la población deje de ser únicamente consumidora de tecnologías y pase a ser creadora, usando los artefactos digitales como herramientas privilegiadas.

En esta propuesta, es fundamental recuperar la experiencia de los educandos, sus formas de hacer y de expresarse con el fin de acompañarla en el logro de usos efectivos en proyectos personales o colectivos. Conocer a fondo los algoritmos y a la vez aprender los conceptos fundamentales de la computación permite el dominio sobre las herramientas digitales; de este modo, desde la conciencia de actora principal es posible involucrarse en procesos de creación que resulten motivadores y poderosos.

- El tercer eje de los saberes digitales es el ejercicio de una ciudadanía digital superadora, que consiste en ayudar a repensar la relación de la ciudadanía en dos dimensiones: con sus pares y con el Estado al que pertenecen. Cuando se dispone de nuevos artefactos de mediación tecnológica y de una red de comunicaciones instantáneas es una necesidad y, a la vez, una obligación desde las instituciones educativas.

A partir de las enseñanzas de Freire se observa que este eje es central con relación a la comprensión crítica del contexto donde se desarrolla cada ser humano. Es fundamental pensar en el desarrollo de capacidades que posibiliten explicar la incidencia de los funcionamientos y diseños de las tecnologías digitales en la cotidianidad.

En este sentido, los temas actuales de la ciudadanía digital están en relación con la apertura y análisis de "cajas negras tecnológicas", como son la inteligencia artificial, las plataformas de Internet, el voto electrónico, los rastros digitales, la identidad y reputación en la red y la vigilancia digital ciudadana, entre otros. 
Si bien estas reflexiones y orientaciones en relación con los saberes digitales no resultan exhaustivas, sí permiten visibilizar tanto la complejidad de cada una de ellas, como su interdependencia. Lejos de miradas celebratorias, se hace énfasis en que la construcción de los saberes digitales no sólo no puede ser dejada en manos de actores privados, sino que requiere de la presencia y lineamientos claros de políticas públicas que conciban a dichos saberes como el eje transversal de la comprensión y crítica de una economía basada en la "industria del algoritmo".

Este movimiento de liberación digital, que también se puede llamar de alfabetización algorítmica, será destinado a quienes no realizan una formación en el campo de la informática o de la programación. Será como iniciarse en la alfabetización como proponía Freire: un proceso para la alfabetización democrática digital.

\section{MOMENTOS DE ALFABETIZACIÓN ALGORÍTMICA FREIREANA}

Como forma práctica de desarrollar los saberes digitales anteriores se toman los momentos del método de Freire, tratando de adaptarlos a las circunstancias del contexto temporal donde nos desarrollamos. Así, se parte del momento de la prealimentación, donde el proceso se divide en tres fases:

1. Concientización: alfabetizar es concienciar

2. Dialogicidad

3. La voz como empoderamiento

\section{Concientización: alfabetizar es concienciar}

Concienciar es un acto que consiste en la convergencia de los sujetos con su historicidad, con su contexto, tal como describe Martínez-Pérez (2020: 390): "nos encontramos sumidos en un modelo educativo de carácter tradicional, pero adulterado con tecnología reproductiva del siglo XXI, que no hace sino recrear una 'educación del escaparate', más orientada al marketing y al ensalzamiento tecnocrático que al humanístico”.

El modelo memorístico se muestra oculto tras una fina capa de barniz; se apropia del concepto de innovación para aplicarse a palabras anglosajonas, dispositivos electrónicos y un movimiento velado de privatización de la educación.

Los algoritmos y el pensamiento computacional pueden suponer un nuevo modelo educativo, donde los principios de la alfabetización de Freire se conjuguen con las necesidades ciudadanas en un contexto tecno-social; que haga posible la transformación de un modelo de enseñanza-aprendizaje industrial a uno más contemporáneo, basado en lenguajes de programación que se alejen del aprendizaje lineal y predecible para dar paso a una gestión moderna desde la teoría del caos y el efecto mariposa.

La alfabetización algorítmica se muestra más necesaria que nunca en una sociedad maleable que vive hipnotizada por la cultura de la inmediatez y una política de decisiones en teoría propias pero que, en realidad, son 
diseñadas por los grandes grupos de poder con el objetivo de cumplir sus expectativas y cubrir sus necesidades económicas, políticas y sociales.

Freire propone, desde sus principios de alfabetización, que con una base constructiva desde la cual partir para hacer frente a un mundo copado por "soluciones tecnocráticas", con una sociedad alfabetizada y la entrada de estos conceptos en la escuela, se puede sacar gran partido para el fomento de una sociedad de la esperanza.

\section{Dialogicidad}

La influencia de los algoritmos y la inteligencia artificial, apoyada por la plataformización en la sociedad informacional, sostiene una doble vía de actuación con un resultado muy diferenciado: 1) si, como usuario, se tiene la capacidad de elegir las propias relaciones; o 2) si éstas vienen impuestas por los intereses y necesidades del mercado que promueve un nuevo modelo de "esclavitud" y dogmatización encubierto que deriva del estrechamiento y aislamiento social.

Se construye un relato en el cual se hace creer en la autonomía, en la toma de decisiones, sin embargo, la humanidad es manejada por algoritmos que son, a su vez, los que pueden revertir la situación y, desde su potencialidad, unir a personas con intereses comunes que puedan transformar la realidad y crear un modelo de sociedad más equitativo, accesible y democrático.

Este proceso de transformación no es ajeno a las disputas y los desencuentros, sin embargo, se sostiene en "la virtud revolucionaria, que consiste en la convivencia con los diferentes para que se pueda luchar mejor contra los antagónicos" (Freire, 2002: 57). En el caso de la alfabetización algorítmica se observan diferentes posturas en relación con la tecnología; nuevos términos que pueden resultar complejos de comprender. Ciudadanas y ciudadanos que ceden sus derechos de atención y permanencia, sus gustos y sus anhelos ¿a cambio de qué? ¿Este intercambio es justo y equitativo? Quizás no exista un intercambio, sino una relación unidireccional disfrazada de un proceso de comunicación.

\section{El derecho a la voz como empoderamiento}

El empoderamiento es el objetivo principal que todo alfabetizador potenciará para dar lugar a la transformación social desde la base; para "desafiar las estructuras opresoras y nutrir las relaciones que habiliten a la gente para fortalecer el control sobre sus vidas para beneficio de todos" (Torres, 2009: 92).

Freire afirma que:

La profundidad de la significación de ser ciudadano pasa por la participación popular, por la voz. Cuando digo voz, me refiero a algo distinto de lo que estoy haciendo aquí. No se trata de hablar o recitar. La voz es el derecho a preguntar, a criticar, a sugerir. Eso es tener voz. Tener voz es una presencia crítica en la historia. Tener voz es estar presente, no ser presente. En las experiencias autoritarias el pueblo no está presente, es representado. Pero no representa (Freire, 2016: 109). 
En un mundo gobernado por algoritmos e inteligencia artificial se sigue promoviendo la programación predictiva con base en la gran masa: conseguir alcanzar los objetivos hegemónicos sin preocuparse de las necesidades individuales; dejar atrás a aquéllos que presentan más dificultades y promover una voz homogénea que se muestre aceptada socialmente y en la que se pierden u olvidan todas aquellas voces divergentes que merecen ayuda, respeto y dignidad.

\section{GUBERNAMENTALIDAD ALGORÍTMICA}

La evolución de los algoritmos se asemeja al ideario de Turing, presentado en el simposio de Hixon en 1948 donde, junto a otros teóricos, reflexionaba sobre la metáfora del ordenador: mente-software, cuerpo-hardware. Además, la reflexión se centraba en un intenso debate sobre los mecanismos cerebrales y la creación de un algoritmo complejo que fuera capaz de resolver tareas como acertijos o jugar ajedrez. En la actualidad los algoritmos han superado con creces aquellas ideas que se intentaba desarrollar con el nacimiento de la inteligencia artificial.

Más allá de su definición matemática, el algoritmo tiene una dimensión sociopolítica en el universo social. Los algoritmos son instrucciones diseñadas por un programador que procesan los datos que los usuarios arrojan y después se devuelve aquello que se espera ver:

En adelante y a gran velocidad, un número creciente de dominios... se encuentran equipados por algoritmos. Éstos organizan y estructuran las informaciones, nos ayudan a tomar decisiones o automatizan procesos que teníamos la costumbre de controlar nosotros mismos (Cardon, 2018: 17).

Es necesario retomar la idea de Canclini (2020) sobre la opacidad de los datos y cómo ese proceso es asimétrico y desigual; quienes controlan los algoritmos, además de conocer cómo funcionan, controlan cómo programarlos para que evolucionen de forma automática con el objetivo de monetizar todo aquello que pasa en la red de redes.

En su origen, los algoritmos no compartían las funcionalidades y los objetivos que actualmente desempeñan a golpe de clic. Todos los datos residuales que se generaban en las plataformas se transformaron, mediante el capitalismo de la atención (Wu, 2016), en el objeto deseado de las grandes big tech.

Si bien en tiempos del paradigma industrial, tanto el trabajo organizado en líneas de producción eficientes como los dispositivos disciplinarios fueron elementos de control y gobierno asociados a lo corporal, más que a lo mental, con la llegada de la biopolítica ya no es necesario moldear ni encerrar a los sujetos. Ahora, en los tiempos del algoritmo se ejercitan otras formas menos explícitas de control y poder que tienden a que exista una gestión del orden poblacional mucho más sutil y efectiva. Y aquí, en este territorio, donde se modulan mentes, más que se castigan cuerpos, el algoritmo es la base del nuevo modelo planetario de vigilancia en pos de proteger y hacer crecer vorazmente los intereses del capitalismo informacional. 
Este ejercicio de poder actual, donde los datos digitales son comunicados y procesados a velocidades intensas, es denominado por algunos autores "gubernamentalidad algorítmica". Gendler (2016), citando a Rouvroy y Berns, la define como:

...un cierto tipo de racionalidad (a)normativa, o (a)política que reposa sobre la recolección, agregación y análisis automatizado de datos en cantidades masivas, de modo de modelizar, anticipar y afectar por anticipado comportamientos posibles... la gubernamentalidad algorítmica no produce cualquier subjetivación, sino una que crea modelos de comportamiento (perfiles) supraindividuales a base de [sic] datos infraindividuales (Gendler, 2016: 42).

La otra novedad es que la gubernamentalidad algorítmica puede ser ejercida tanto por gobiernos como por empresas privadas. Así, de nuevo el algoritmo es el "engranaje" de un nuevo tipo de sociedad donde los datos cedidos, con y sin conciencia, por millones de personas, son procesados por estos sistemas binarios que aprenden de sus propias experiencias y sacan el máximo provecho posible en función de, por un lado, corregir desvíos de conductas y, por otro lado, de alimentar esta nueva versión del mercado.

\section{CONSIDERACIONES FINALES:}

\section{LA EDUCACIÓN COMO CONTRAPODER}

Es el momento de despertar a esta nueva realidad que controla y vigila las acciones del día a día como lavar la ropa, comprar y leer libros, poner en marcha el aspirador y programar la calefacción, entre un sinfín de actividades. Los algoritmos han conquistado los espacios privados de las personas mediante las acciones cotidianas.

No se debe olvidar la oralidad y su protagonismo en todo este proceso. $\mathrm{Si}$ bien en líneas anteriores hablábamos de dar voz a quienes no la tienen, como proceso emancipador, también en la carrera por conquistar la oralidad toma posición el desarrollo del algoritmo, ya que intenta conquistar los espacios de las acciones cotidianas mediante la diseminación de dispositivos que recogen los registros sonoros. Los algoritmos han llegado para quedarse.

Y también pueden aportar avances y facilidades para la mejora de la calidad de vida de la gente, mediante el aprendizaje automático, que es capaz de generar nuevas conexiones y mejorar experiencias como estacionar un coche, programar y organizar ciudades inteligentes, así como proteger el medio ambiente mediante predicciones o al informar acerca de la toma de conciencia de las acciones humanas que van en contra de la sostenibilidad de los ecosistemas que se cohabitan.

El desarrollo de las tecnologías informáticas y la ampliación de la capacidad de procesamiento de los dispositivos, junto con el crecimiento de la velocidad de conexión han facilitado aún más el almacenamiento y mercantilización de los datos. Pero este proceso puede aún ampliarse en un futuro no muy lejano con el ordenador cuántico y la red 5G. 
Se requiere una alfabetización algorítmica que actúe como contrapoder desde el ecosistema educativo; que llegue a cada estudiante con base en sus intereses, necesidades y capacidades para sacar lo mejor de cada persona. Una alfabetización algorítmica que promueva la recuperación de la voz de una ciudadanía sin voz. Que impulse, de una vez por todas, un empoderamiento ciudadano real y significativo.

Un ejemplo concreto se puede encontrar en aplicaciones y herramientas orientadas a "perfeccionar" el modo de leer de los niños; miden la velocidad, comprensión, atención... y elaboran, con base en inteligencia artificial, unos parámetros a los cuales deben llegar los infantes para conseguir una buena puntuación, aceptación académica, progreso teórico. ¿Qué ocurre con los estudiantes que leen a un ritmo diferente?, ¿qué ocurre con los estudiantes que presentan discapacidad?, ¿los algoritmos promueven la inclusión o la exclusión?

En el proceso de alfabetización algorítmica se toma como punto de partida el algoritmo en función de cada contexto, y se problematiza sobre sus implicaciones en cada realidad; se construyen los cimientos sobre los cuales edificar otra educación, centrada en la defensa de la libertad individual y colectiva frente al asedio de la digitalización privada de los grandes grupos de poder que, de la mano de las grandes plataformas, ocupan los espacios públicos en los que nos educamos desde edades tempranas.

Difícilmente los algoritmos podrán erradicarse... son más que instrucciones: por un lado, está su definición matemática y, por el otro, operan como catalizadores de nuestra identidad en el ciberespacio y nos encierran en un espacio ilusorio. Si en un momento anterior los medios tecnológicos difundieron un relato homogéneo, en la actualidad, de la mano de los algoritmos, cada individuo se multiplica a sí mismo a través de sus propios clics. Ante los cambios emergentes que se están dando en los últimos años, se hace necesaria la creación y conceptualización de nuevos términos, de la misma forma que en su momento Freire activó la palabra generadora y el universo vocabular en el proceso de alfabetización.

\section{REFERENCIAS}

APARICI, Roberto y Jorge Martínez-Pérez (2021), El algoritmo de la incertidumbre, Barcelona, Gedisa.

Aparici, Roberto y David García-Marín (2018), "Prosumidores y emirecs: análisis de dos teorías enfrentadas", Revista Científica de Comunicación y Educación, vol. 26, núm. 55, pp. 71-79.

Bordignon, Fernando Raúl Alfredo (2019), "Saberes digitales en la educación primaria y secundaria de la República Argentina”, Espiral. Revista de Docencia e Investigación, vol. 8, núm. 2, pp. 79-90.

CARdon, Dominique (2018), Con qué sueñan los algoritmos, Madrid, Dado ediciones.

CAStells, Manuel (1998), La era de la información. Economía, sociedad y cultura, vol. 1: La sociedad red, Madrid, Alianza Editorial.

Castells, Manuel (2001), "Epílogo: informacionalismo y la sociedad red", en Pekka Himanen, La ética hacker y el espíritu de la era de la información, Barcelona, Destino, pp. 110-124.

Dewey, John (1995), Democracia y educación: una introducción a la filosofía de la educación, Madrid, Ediciones Morata. 
Freire, Paulo (1970), Cultural Action for Freedom, Cambridge, Harvard Educational Review.

Freire, Paulo (1993), Pedagogía de la esperanza, México, Siglo XXI.

Freire, Paulo (2002), Pedagogía de la esperanza, un reencuentro con la pedagogía del oprimido, Buenos Aires, Siglo XXI Editores.

Freire, Paulo (2016), El maestro sin recetas: el desafío de enseñar en un mundo cambiante, Buenos Aires, Siglo XXI Editores.

García Canclini, Néstor (2020), Ciudadanos reemplazados por algoritmos, Bielefeld, Bielefeld University Press.

Gendler, Martín Ariel (2016), "Datos, algoritmos, neutralidad de la red y sociedades de control”, IV Simposio Internacional LAVITS, CABA, 21 de noviembre de 2016, Buenos Aires.

Martínez-Pérez, Jorge (2020), Educación, mercado e innovación. El sector privado y las metodologías innovadoras. "Flipped Classroom", Tesis de Doctorado, Madrid, UNED.

Martínez-Pérez, Jorge y Roberto Aparici (2021), "La educación del escaparate. ¿Avance para todos o para unos pocos? (QR)", en Roberto Aparici y Jorge MartínezPérez (coords.), El algoritmo de la incertidumbre, Madrid, Gedisa, pp. 68-71.

Pizzi, Jovino (2018), "Democracias bajo efectos clickbait: la gramática pronominal como respuesta a la virtualidad-tecnocrática", Veritas, núm. 39, pp. 33-53.

Rouvroy, Antoniette y Thomas Berns (2015), "Governamentalidade algorítmica e perspectivas de emancipação: o díspar como condição de individuação pela relação?", Revista Eco-Pos, vol. 18, núm. 2: Tecnopolíticas e vigilancia, pp. 36-56.

Slomp, Paulo Francisco (2018, junio, 24), "Diálogo entre Paulo Freire y Seymour Papert" [video], en: https://www.youtube.com/watch?v=41bUEyS0sFg (consulta: 15 de septiembre de 2021).

Stramiello, Clara Inés (2005), “¿Una educación humanista hoy?”, Revista Iberoamericana de Educación, vol. 36, núm. 8, pp. 1-5.

Torres, Analí (2009), "La educación para el empoderamiento y sus desafíos", Sapiens. Revista Universitaria de Investigación, vol. 10, núm. 1, pp. 89-108.

VAN DijcK, José y Thomas Poell (2018), "Social Media Platforms and Education", en Jean Burgess, Alice Marwick y Thomas Poell (eds.), The SAGE Handbook of Social Media, Londres, Sage, pp. 579-591.

Wu, Tim (2016), The Attention Merchants: The epic scramble to get inside our heads, Nueva York, Alfred A. Knopf Vintage.

Zuboff, Shoshana (2015), "Big Other: Surveillance capitalism and the prospects of an information civilization”, Journal of Information Technology, vol. 30, núm. 1, pp. 75-89.

Zuboff, Shoshana (2019), La era del capitalismo de la vigilancia. La lucha por un futuro humano frente a las nuevas fronteras del poder, Barcelona, Paidós Estado y Sociedad.

Zukerfeld, Mariano (2020), "Bits, plataformas y autómatas. Las tendencias del trabajo en el capitalismo informacional", LAT. Revista Latinoamericana de Antropología del Trabajo, vol. 4, núm. 7, pp. 1-50. 